\title{
ESTUDO SOBRE AVALIAÇÃO DE DESEMPENHO DE ENFERMEIRAS - REFERENCIAL TEÓRICO (PARTE I)
}

\author{
Paulina Kurcgant *
}

KURCGANT, P. Estudo sobre avaliação de desempenho de enfermeiras: referencial teórico - Parte I. Rev. Esc. Enf. USP, São Paulo, 20(1):39-54, 1986.

Nesta primeira parte do estudo é apresentado o que há na literatura profissional sobre a evolução da Administração de Pessoal segundo as diferentes escolas e teorias administrativas e $\dot{e}$ discutida a interação individuo-organização desde o enfoque mecanista até o enfoque sistêmico. O enfoque sistêmico é explicado pelo conceito sociológico das organizações. A avaliãcao de desempenho é estudada como parte integrante da administração de recursos humanos que, especificamente na área de saúde, é considerada um subsistema do sistema de saúde. Como referencial teórico, especifico da avaliação de desempenho, são analisados os objetivos de avaliação, os métodos $e$ técnicas utilizados, o preparo dos elementos que participam do processo avaliativo, a freqüência em que $\dot{e}$ realizada $e$ os sentimentos que envolvem $o$ avaliador $e$ o avaliado. No âmbito de atuação da enfermagem é evidenciado o que ocorre na avaliação de desempenho das enfermeiras, em outros paises, e é salientada a escassez de estudos sobre o assunto ma realidade brasileira.

Situações simples, em que um homem planeja e executa seu próprio trabalho, são familiares, mas, quando essa tarefa se expande até o ponto em que se faz necessário o esforço de numerosas pessoas para levá-lo a cabo, a simplicidade desaparece, tornando-se necessário o desenvolvimento de processos especiais para aplicação do esforço coletivo.

Um dos processos é a criação de sistemas planejados, que congreguem esforços coletivos, e onde cada participante tem um papel definido a desempenhar. Eșses sistemas assim planejados são denominados organizações, em qualquer área de atividade humana (SIMON et alii ${ }^{81}$ ).

Segundo BLAU \& SCOTT ${ }^{13}$, entretanto, o fato de uma organização ter sido formalmente estabelecida não significa que todas as atividades e interações de seus membros estejam estritamente determinadas. Os grupos constituintes dessas organizações, como todos os grupos, adquirem seus próprios hábitos, valores, normas e relações sociais, desenvolvendo a chamada «organização informal» concomitante à «organização formal» já estabelecida.

KATZ \& $\mathrm{KAHN}^{34}$, analisando esse fato, consideram que toda organização cria sua própria cultura ou clima, com seus próprios tabus, costumes e crenças. O clima ou cultura da organização reflete tanto

\footnotetext{
* Enfermeira. Professor Assistente Doutor do Departamento de Orientaçăo Profissional da Escola de Enfermagem da USP - disciplina Administractio Aplicada a Fnfermacem.
} 
as normas e valores da organização formal, como sua reinterpretação no sistema informal.

Faz-se necessário reconhecer, também, que não é possível isolar qualquer organização do ambiente cultural da sociedade onde está inserida.

Assim como a sociedade tem uma herança cultural, as organizações sociais também possuem padrões distintos de sentimentos e crenças coletivas, que são transmitidas a todos os membros do grupo.

Baseados nessa visão sociológica, administradores passaram a admitir como sendo três os «elementos constituintes» ou «dimensões básicas» da organização. SOUZA ${ }^{64}$ considerou-os como «preceitos», «tecnologia», e «caráter» e BERNARDES ${ }^{10}$, como «instituição», «tecnologia» e «expressão». Esses autores definiram preceitos ou instituição como a autoridade e o conjunto de regulamentos e valores explícitos ou implícitos que regem a vida organizacional; tecnologia, como o conjunto de instrumentos e processos utilizados no trabalho organizacional, inclusive em suas relações com o ambiente externo; e caráter ou expressão, como o conjunto de manifestações afetivo-volitivas e espontâneas dos indivíduos que compõem a organização.

A predominância de um dos elementos ou dimensões sobre as demais resulta da interação indivíduo/organização. É essa interação, portanto, que caracteriza a organização e define o seu desempenho na produção de bens ou serviços.

$\mathrm{Na}$ análise histórica do processo de interação indivíduo/organização encontramos a ênfase administrativa, ora tendendo para a organização, ora tendendo para o indivíduo.

SIMON ${ }^{60}$, argumentando a respeito, afirma que a organização é importante porque é o ambiente organizacional que envolve os indivíduos e gera a maioria das forças modeladoras do seu comportamento e orientadoras de suas potencialidades.

ARGYRIS ${ }^{3}$ discute a hipótese de que a incongruência entre o indivíduo e a organização pode proporcionar a base para um contínuo desafio que, à medida em que é satisfeito, ajuda o ser humano a intensificar seu próprio desenvolvimento e a criar organizações mais viáveis e eficientes.

Para GROS \& AUMONT ${ }^{27}$, a empresa é, talvez, uma das células sociais onde se evidencia melhor o paradoxo das situações em que os homens do nosso tempo têm de viver; consideram que, para a organização, os imperativos mais vitais e mais urgentes continuam sendo os que se relacionam com os homens e o seu trabalho; afirmam, ainda, que qualquer unidade de produção ou de serviço, sejam quais forem os progressos técnicos, é e será feita pelos homens nela integrados. Tecnicamente o trabalho deve realizar-se e ser bem executado; é preciso que a empresa vença. No plano humano, é preciso que os homens que trabalham não só não se destruam, como ainda se desenvolvam. O des- 
tino da empresa e a satisfação dos homens estão estreitamente relacionados.

OWEN e URE, no século XIX, foram os pioneiros a considerar o fator humano no esforço da produção industrial. OWEN, por volta de 1800 , preocupou-se com o problema das necessidades dos trabalhadores e URE publicou, em 1835, um livro intitulado «Filosofia na Indústria», no qual apontava, aos industriais da época, o fator humano como merecedor de considerações especiais pela sua importância no processo de produção.

Somente no início deste século, entretanto, é que se pode notar um novo esforço no sentido de considerar o «homem» como fator importante na produção.

Para TOLEDO ${ }^{69}$, o órgão de recursos humanos, como setor definido das organizações, teve seu aparecimento no início do século, mas, sua real evolução deu-se na década dos 20. O fortalecimento do movimento

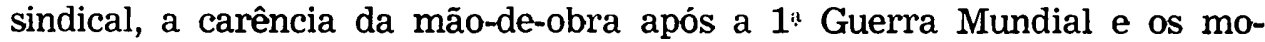
vimentos filosóficos dos anos 30, aliados aos primeiros trabalhos de Sociologia do Trabalho, forneceram os subsídios éticos e científicos para a evolução da Administração de Recursos Humanos. Viu-se, com esses trabalhos, o quanto as relações humanas afetavam a produtividade; concluiu-se com eles que, se fossem melhoradas as relações humanas dentro de uma empresa, seria aumentada a produção e, se as aspirações básicas do homem fossem satisfeitas, haveria aumento da realização pessoal.

Para LAWLER \& PORTER ${ }^{39}$ foi a ênfase nas relações interpessoais e na satisfação no trabalho, na década dos 30 , que forneceu importante estímulo para os estudos referentes às atitudes do homem no trabalho e ao comportamento humano nas organizações.

Para SAYLES ${ }^{59}$, a escola das relações humanas evidenciou, nos anos 40, a modificação, pelas ações das pessoas, de certos princípios administrativos até então aplicados segundo ponto de vista absolutamente racional, sem considerar a interferência das ações humanas.

Nas décadas de 50 e 60, LIKERT ${ }^{40}$ e McGREGOR ${ }^{47}$ defenderam a idéia de que as organizações, para serem eficazes, precisavam ser vistas como grupos de pessoas que interagiam com relações de apoio recíproco. LIKERT ${ }^{40}$, numa pesquisa para avaliar a eficácia administrativa, concluiu que os supervisores que obtinham os melhores índices de produção voltavam sua atenção, basicamente, para os aspectos humanos dos problemas de seus subordinados, empenhando-se na constituição de grupos efetivos de trabalho, tendo por meta um alto nivel de desempenho.

McGREGOR ${ }^{47}$, analisando a tarefa administrativa sob ponto de vista «convencional» no referente ao direcionamento da energia humana, estabeleceu o que chamou de teoria «X». Essa teoria se baseou em postulados que, embora não explícitos nas organizações, eram difundidos entre os administradores, a ponto de dirigirem suas decisões na gerência de pessoal. Segundo essa teoria, cabia à administração organizar, controlar e modificar o pessoal, uma vez que o homem era considerado como 
um ser indolente, sem responsabilidade e naturalmente resistente a mudanças. Baseado no trabalho de MASLOW, que estabeleceu a hierarquia das necessidades básicas do homem, e na análise da motivação, McGREGOR demonstrou ser inadequada a abordagem «convencional» da administração e criou a teoria «Y», que preconizava, como responsabilidade da organização, propiciar condições necessárias à obtenção dos objetivos organizacionais e individuais, uma vez que, segundo essa teoria, os indivíduos são considerados ativos e com capacidade para assumir responsabilidade.

OUICHI $\cdots$, já na década de 80 , fez uma análise comparativa das estruturas administrativas e da dinâmica organizacional de empresas japonesas e americanas, observando maior produtividade e satisfação dos funcionários nas empresas japonesas. Estabeleceu, então, a teoria «Z», cuja filosofia é a de abordagem participativa, segundo a qual a maior produtividade advém de melhor coordenação e não de aumento de esforço físico; a melhoria na coordenação só ocorre se todos os empregados se empenharem na análise, no planejamento e no processo de tomada de decisão; o maior envolvimento dos funcionários resulta em maior desenvolvimento da organização e esta, conseqüentemente, deve retribuir, proporcionando melhores condições de trabalho aos funcionários.

WARLICH ", analisando os fenômenos organizacionais gerados pelo envolvimento indivíduo/organização, explica a evolução histórica segundo as teorias organizacionais. Assim, a fase da administração em que a ênfase era a produção e o homem era considerado apenas como um recurso para o alcance dos objetivos organizacionais (Teoria «X» de McGREGOR), é por ela explicada pela influência da «teoria tradicional» ou «formal» da organização; a preocupação com o elemento humano nas organizações e a crença de que as relações humanas afetavam a produção (Teoria «Y» de McGREGOR) é analisada como a fase de influência da «teoria comportamentalista»; e a visão sociológica da interdependência existente entre individuo, organização e sociedade (Teoria «Z» de OUICHI ${ }^{5 i}$ ) é explicada pela aplicação da «teoria de sistemas» às organizações.

A influência da teoria de sistemas e da teoria comportamentalista no desempenho administrativo é hoje aceita pelas organizações, que visam, concomitantemente, a obtenção de metas organizacionais e o desenvolvimento de seu pessoal.

Estudiosos da administração atual, como ETZIONI ${ }^{20}$, KATZ \& $\mathrm{KAHN}^{34}$ e KAST \& ROSENZWEIG ${ }^{33}$, admitem as organizações como sistemas sociais abertos que fundamentam o desenvolvimento organizacional em duas forças: as ciências comportamentalistas, que realçam o sistema psicossocial, e as ciências da administração, que dão ênfase à quantificação dos modelos matemáticos.

$\mathrm{Na}$ área de saúde, MEJIA 49 adota o enfoque sistêmico e considera o sistema de saúde «um mecanismo que transforma os recursos gerais de uma sociedade (conhecimento, pessoal e capital) em serviços especiais, cuja finalidade é atender os problemas de saúde dessa comunidade». 
Considera, ainda, o sistema de pessoal de saúde, pela sua importância e complexidade, um subsistema do sistema geral de saúde.

TEJADA-DE-RIVERO ${ }^{68}$ enfatiza o papel do pessoal em saúde, quando considera os serviços de saúde «uma indústria com grande densidade de mão-de-obra e onde o pessoal é um elemento importantíssimo».

Para a OMS ${ }^{50}$, os problemas de pessoal de saúde devem ser abordados de forma integral, mediante uma política global de desenvolvimento de pessoal, que estimule o progresso do indivíduo dentro da organização; considera, ainda, que deve ser promovida a integração das aspirações individuais com os objetivos da organização.

Para HALL \& MEJIA *9, o problema fundamental da prestação de serviços de saúde, na América Latina, reside na dicotomia quase completa entre o processo de organização dos serviços de saúde e o desenvolvimento do pessoal dessa área; além disso, os elementos que constituem o processo de desenvolvimento (planejamento, formação e administração de pessoal) estão, em geral, mal coordenados.

A administração de pessoal, como um dos elementos integrantes do processo de desenvolvimento de pessoal, abarca todo o relacionamento do individuo com o emprego e controla as variáveis organizacionais que determinam o ambiente de trabalho.

A boa administração de pessoal, segundo MEJLA ${ }^{49}$, permite a redução da inoperância, incentiva a motivação, remunera equitativamente, utiliza o pessoal de forma eficaz e aumenta a estabilidade no emprego. Segundo ele, as experiências vividas pelo pessoal, nas organizações de prestação de serviços de saúde, influem nas atitudes do mesmo a respeito do sistema de saúde e determinam a maneira como cumpre suas funções.

No Brasil, a falta de uma política global de desenvolvimento de pessoal de saúde permite, às instituições de prestação de serviços, a livre determinação da política de pessoal por elas adotadas.

É necessário, portanto, para que se efetive o processo de desenvolvimento de pessoal de saúde, que a política de pessoal nas organizações promova o aprimoramento desse pessoal e incentive a adoção de técnicas, métodos, estratégias e decisões gerenciais que melhor atendam a esse processo. E necessário que a organização conheça seus homens e a influência do desempenho de cada um na composição da força de trabalho.

Já em 1948, WIENER, no livro «Cybernetics», estudando a maximização da rapidez e da exatidão do desempenho humano, conceituou o homem como um sistema auto governado, em termos fisiológicos e psicológicos; no mesmo ano SHANNON, em «The Mathematical Theory of Communication», estabeleceu os conceitos básicos da informação. Segundo o enfoque cibernético, que é o controle por realimentação ( feedback control») associado ao conceito de informação, o desempenho de qualquer tarefa pode ser caracterizado como uma sequência de entradas («input»), ação e realimentação («feedback»). 
É, ainda, baseados nesse principio cibernético, que os administradores admitem, como primeira etapa de um processo de desenvolvimento de pessoal, o conhecimento do desempenho humano nas organizações.

Para AQUINO \%, o conhecimento do desempenho humano nas organizações envolve, em termos práticos, atividades específicas de avaliação de desempenho; essas atividades, entretanto, devem estar inseridas num programa de interação indivíduo/organização que tenha, como base, atitude favorável da administração em relação aos empregados, e crença na sua potencialidade e no seu direito de terem suas necessidades atendidas; uma estrutura organizacional facilitadora e não restritiva do desempenho humano, que permita a cada um chegar ao máximo possível de rendimento; um plano de recompensas com base nas motivações do funcionário; e a decisão destes de contribuirem para o alcance dos objetivos organizacionais.

Na realidade brasileira, as organizações de saúde, de modo geral, desenvolvem atividades para avaliar desempenho de pessoal de forma isolada e profundamente desvinculadas de qualquer idéia de integração individuo/organização ou de programas de desenvolvimento de pessoal.

Na Enfermagem, como serviço integrante das organizações de saúde, também se verifica que os resultados da avaliação de desempenho não têm sido utilizados na retroalimentação do processo de aprimoramento profissional.

Para que a instituição efetive a avaliação como estratégia de desenvolvimento de pessoal, é necessário que seja feito, preliminarmente, o diagnóstico da situação da organização naquele momento, ou seja, que sejam conhecidas a filosofia da instituição, as características dos recursos humanos e a dinâmica da organização.

Somente após esse diagnóstico, se torna possivel a implementação de um programa de avaliação de desempenho, uma vez que os componentes desse programa, isto é, os objetivos da utilização da avaliação, a determinação dos elementos responsáveis, os métodos e as técnicas adotadas, o preparo específico do pessoal, o instrumento utilizado e a freqüência da avaliação devem ser compatíveis com a filosofia da instituição, com as caracteristicas dos recursos humanos e com a dinâmica da organização na qual o programa será desenvolvido.

Os motivos que levam a organização a utilizar a avaliação de desempenho na administração de seu pessoal são bastante discutidos por administradores e constituem, segundo esses administradores, os objetivos implícitos ou explícitos dos programas de avaliação.

Para McGREGOR ${ }^{48}$ são três os motivos que levam a organização a adotar planos de avaliação de desempenho: o primeiro atende à organização e proporciona meios para determinar aumentos de salários, promoções, transferências e, algumas vezes, remoçōes e demissōes; os outros dois se referem ao avaliado e ao avaliador. Para o avaliado, a avaliação fornece informações sobre como sua atuação é vista e sentida, 
o que orienta seu auto-desenvolvimento e para o avaliador serve como retroalimentação do sistema de desenvolvimento de pessoal.

Para TOLEDO ${ }^{69}$, PATZ ${ }^{56}$, AQUINO ${ }^{2}$, SANTOS ${ }^{58}$ e JUCIUS ${ }^{\circ 2}$, os objetivos dos programas de avaliação de desempenho também são organizacionais e individuais, embora, por não serem freqüentemente explícitos nos programas e raramente discutidos em toda a organização, tendem a interpretações quase individualizadas.

Segundo LUCENA ${ }^{42}$, CHIAVENATO ${ }^{16}$, BERGAMINI ${ }^{6}$ e COELHO NETO ${ }^{17}$, os objetivos dos programas de avaliação de desempenho devem estar essencialmente voltados para a tentativa de medir o potencial humano, desenvolver esse potencial e permitir a efetiva participação de todos os elementos nas decisões organizacionais.

$\mathrm{Na}$ área de enfermagem, SOUTH ${ }^{63}$, REZLER \& STEVENS ${ }^{57}$, BERGLAS ${ }^{12}$, DAU ${ }^{18}$, WILEY ${ }^{72}$ e MARRINER ${ }^{45}$ consideram que os programas de avaliação de desempenho, nos Estados Unidos, objetivam manter ou melhorar o desempenho da equipe de enfermagem e fornecer à chefia dados administrativos para a tomada de decisão.

$\mathrm{Na}$ verdade, os objetivos dos programas de avaliação explicam o porque de se fazer essa avaliação; entretanto, as respostas referentes a quem faz a avaliação, como e quando fazê-la também devem ser analisadas quando se pensa em avaliação como estratégia de desenvolvimento de pessoal e não como atividade burocrática e isolada.

A importância de quem faz a avaliação transcende a pessoa do avaliador, uma vez que os responsáveis pelos resultados da avaliação são todos aqueles que participam da implementação do programa, em todos os niveis da estrutura organizacional.

Os administradores, entretanto, discutem, mais largamente, a responsabilidade dos elementos que atuam a nível operacional da avaliação.

Para BERGAMINI ${ }^{7}$, os responsáveis pela avaliação são todos aqueles que exercem cargo ou função de chefia e aos quais cabe emitir parecer sobre o subordinado.

Para FLIPPO ${ }^{21}$, MOORE \& SIMENDINGER ${ }^{51}$ e HAMRIC et alii ${ }^{28}$, na maioria das situações que envolvem avaliação, o avaliador é o chefe imediato do homem a ser avaliado. Outras possibilidades encontradas são: a participação de mais de um chefe na avaliação, ou uma comissão responsável pela emissão do parecer, ou os subordinados avaliarem seus chefes e, uma última, um empregado ser avaliado pelo seu próprio grupo.

Para a efetivação da avaliação, contudo, não basta a determinação dos responsáveis; é necessário que seja promovida a prontidão dos Avaliadores para esse fim, uma vez que, segundo os administradores, a avaliação não atingirá seus objetivos se os avaliadores não estiverem devidamente preparados para desempenharem esse papel.

$\mathrm{Na}$ nossa realidade, a dicotomia existente entre o sistema de ensino e o da prática é um sério obstáculo para o profissional quando necessita 
exercer esse tipo de atividade, uma vez que não recebe, durante sua formação profissional, preparo específico para executar atividades de avaliação de desempenho; por outro lado, também há pouco empenho, por parte das organizações de prestação de serviços de saúde, no preparo desse pessoal.

Segundo LUCENA ${ }^{13}$, o avaliador, para estar preparado, deve conhecer o avaliado como «homem» e como «profissional», isto é, deve ter conhecimentos suficientes para perceber e analisar o comportamento humano, como também para analisar, tecnicamente, o trabalho realizado pelo avaliado.

Para BERGAMINI ${ }^{8}$, os programas que visam o treinamento de avaliadores devem promover, também, o auto-conhecimento desses elementos, pois, é imprescindivel que eles conheçam a si mesmos, antes de desempenharem o papel de avaliadores.

$\mathrm{Na}$ opinião de $\mathrm{AQUINO}{ }^{1}$, TOLEDO ${ }^{69}$ e FLIPPO ${ }^{21}$, devem ser discutidos com o avaliador o «como», o «porque» e o «quando» fazer avaliação, e a importância desse processo para a organização e o indivíduo.

$\mathrm{Na}$ área de enfermagem, BERNARD \& SCHUETTE ${ }^{11}$, utilizando a avaliação de desempenho no hospital onde trabalhavam, verificaram a necessidade de serem orientados não só os avaliadores, como também todas as pessoas envolvidas no processo de avaliação.

WILEY ${ }^{22}$, GAUERKE ${ }^{22}$, MARRINER ${ }^{46}$, O'DONOVAN $^{33}$, HESLIN ${ }^{29}$ e KELLY ${ }^{36}$, discutindo o preparo do avaliador na área específica de enfermagem, chamam a atenção para os erros mais freqüentemente cometidos pelos avaliadores, um dos quais é denominado «efeito do halo» e ocorre quando o avaliador dirige a avaliação para um único ponto «alto» ou «baixo» do desempenho do avaliado; outro erro é o chamado «centralização», que ocorre quando todas as características do avaliado são julgadas num único nível de desempenho; outro, ainda, é o «subjetivismo», que acontece quando são atribuídos ao avaliado qualidades ou defeitos que são próprios do avaliador.

A definição de como fazer a avaliação também merece discussão nos diferentes niveis decisórios da estrutura organizacional, principalmente quando se acredita que, para avaliar desempenho, não é suficiente a elaboração e a aplicação de um impresso de avaliação.

A escolha do método que embasa o instrumento de avaliação $t$ as técnicas a serem adotadas pelo avaliador deve resultar da mesma filosofia organizacional que orientou a definição dos objetivos do programa de avaliação; isto porque a escolha do método e das técnicas implica, por exemplo, na maior ou menor participação do avaliado no processo avaliativo.

Administradores como KATZ \& SNOW ${ }^{35}$, HESLIN ${ }^{29}$, GORDON ${ }^{24}$, MAIA-BUSSONS ${ }^{4 !}$, CHIAVENATO ${ }^{16}$, BERGAMINI ", LUCENA *: e 
JESSUP \& JESSUP ${ }^{30}$ recomendam a observação direta e a entrevista como técnicas eletivas a serem usadas pelos avaliadores.

ZOFFOLI ${ }^{i \sigma}$, além das técnicas acima citadas, acrescenta as discussões em grupo, discussões de casos, investigações e compilação e interpretação de registros e informações.

As técnicas que permitem maior participação do avaliado, como entrevista, reuniōes e discussão em grupo, favorecem a obtenção de dados mais precisos, uma vez que permitem ao avaliador melhor compreensão do comportamento observado no avaliado.

A escolha do método de avaliação também requer cuidados e deve refletir a mesma política de pessoal que subsidia os demais elementos do programa.

Para TOLEDO ${ }^{69}$, existem centenas de métodos de avaliação de desempenho e o importante é fazer com que os sistemas sejam adaptados às condições de trabalho da organização.

- BERGAMINI ${ }^{6}$, FLIPPO ${ }^{21}$, DUNNETE ${ }^{19}$, YODER ${ }^{i 5}$, AQUINO ${ }^{2}$, SANTOS ${ }^{58}$, LUCENA ${ }^{42}$, GRILLO ${ }^{25}$ e CHIAVENATO ${ }^{16}$ discutem as vantagens e desvantagens na utilização dos diferentes métodos de avaliação; entretanto, todos os diferentes métodos por eles discutidos, embora com diferentes denominações, se encontram agrupados e conceituados na classificação de WERTHER ${ }^{71}$.

Segundo WERTHER JÚNIOR \& DAVIS ${ }^{i 1}$, os métodos de avaliação de pessoal se classificam em métodos orientados ou para o passado ou para o futuro. Os métodos orientados para o passado têm, como vantagem, o fato de fornecerem aos avaliados retroinformação sobre seus esforços, motivando-os para a melhoria do desempenho futuro e, como desvantagem, o fato de não interferirem no desempenho passado do funcionário.

Como característica comum, esses métodos permitem que um ou mais avaliadores julguem o desempenho do avaliado sem, no entanto, levarem em consideração o julgamento do avaliado a respeito de seu próprio desempenho.

Por esse motivo, segundo PATZ ${ }^{56}$, os teóricos da administração de empresas, vêm, sistematicamente, desacreditando nas versões clássicas dos métodos de avaliação, classificando-os de retrógrados, simplistas e até contraproducentes.

Os métodos orientados para o futuro enfocam o desempenho futuro, avaliando o desempenho passado, o potencial do avaliado e estabelecendo metas para esse desempenho.

Esses métodos têm, como característica comum, permitir que o avaliado, em conjunto com os avaliadores, determine suas metas e analise e discuta suas próprias características de desempenho.

Embora, na prática, a utilização de métodos voltados para o futuro ainda seja pouco difundida, são encontrados, na literatura administrado- 
res que os recomendam (ARGYRIS ${ }^{3}$, OLIVEIRA ${ }^{54}$, SUND \& PICARD ${ }^{\circ 6}$ e KENNEDY ${ }^{37}$ ).

PATZ ${ }^{56}$ chama a atenção para o fato de muitos administradores confundirem a administração por objetivos (A.P.O.) com método de avaliação de desempenho. Segundo PATZ, a avaliação faz a ligação da atuação passada com os resultados obtidos e a A.P.O. está basicamente dirigida para o futuro.

$\mathrm{Na}$ área de enfermagem, GOLIGHTLY ${ }^{23}$, em estudo realizado, verificou que a A.P.O. é uma grande auxiliar na implantação de um sistema de avaliação de desempenho, pois favorece o estabelecimento de objetivos comuns entre avaliadores e avaliados.

SOUTH ${ }^{63}$, WOOLLEY ${ }^{73},{ }^{41}$, BUENO ${ }^{14}$, SIMS ${ }^{62}$, MARRINER ${ }^{46}$, GORDON ${ }^{24}$ e O'DONOVAN ${ }^{53}$ analisaram os métodos mais utilizados pelas enfermeiras americanas e verificaram serem eles métodos voltados para o passado.

Outro componente, e talvez o mais polêmico de todos os elementos componentes do programa de avaliação, é o instrumento de avaliação utilizado.

Essa polêmica se deve ao fato de o instrumento registrar definitivamente o desempenho do avaliado e representar de forma concreta os resultados do programa de avaliação.

Isto faz com que os responsáveis pela avaliação canalizem seus esforços na elaboração do instrumento, acreditando, muitas vezes, que a eficácia da avaliação depende exclusivamente da eficiência desse componente do programa.

BERGAMINI ${ }^{8}$ esclarece muito bem o fato, quando diz que «o sucesso e o fracasso da avaliação de desempenho podem ser determinados pelo instrumento que está sendo utilizado, tendo, porém, esse aspecto do processo avaliativo, tanta importância quanto os demais».

Para JUCIUS ${ }^{32}$, não se deve hipertrofiar o valor do instrumento de avaliação, pois, os formulários são apenas instrumentos que precisam ser cuidadosamente elaborados e adequadamente usados para o alcance dos objetivos propostos.

Na elaboração do instrumento de avaliação, deve-se levar em conta toods os demais componentes do programa e, em especial, os objetivos e o método de avaliação adotados, porque esses dois cornponentes trazem, na sua essência, o «porque» e o «como» está sendo feita a avaliação.

Outro ponto importante na elaboração do instrumento é a determinação dos itens-fatores que devem ser julgados; são estes, também chamados de características, prognosticadores ou rubricas, que delineiam o perfil profissional do elemento a ser avaliado.

Para STOLZ ${ }^{65}$, NEVES ${ }^{52}$ e AQUINO ${ }^{2}$, os prognosticadores devem estar baseados nas atividades executadas pelo funcionário, cuja função 
ou cargo está sendo avaliado pelos resultados do trabalho desenvolvido e não pelas características pessoais dos indivíduos que o exercem.

Muitos instrumentos de avaliação apresentam apenas a indicação das características. Para maior objetividade na avaliação, faz-se necessária a definição dos termos usados na confecção dos prognosticadores.

A enumeracão da graduação que qualifica $n$ desempenho em diferentes niveis também deve ser cuidadosa e, como todo o instrumento, sofre a influência do método de avaliação adotado. Cada grau enumerado deve ser cuidadosamente conceituado, para que sejam evitadas inferências próprias do avaliador.

Administradores como ARNDT \& HUCKABAY ${ }^{4}$, LUCENA 42, TOLEDO $^{69}, \mathrm{KOONTZ}^{38}$, YODER ${ }^{75}$ e PATZ ${ }^{56}$ envidenciam em seus estudos a importância da adequação do instrumento utilizado para o êxito do processo avaliativo.

$\mathrm{Na}$ área de enfermagem, WYMAN \& FERNAU ${ }^{74}$ e BAUMANN \& BERNOIT $^{5}$ e GRONLUND ${ }^{26}$ discutem os passos a serem adotados na elaboração do instrumento de avaliação e TATE ${ }^{67}$, nos Estados Unidos, realizou um estudo sobre a aplicação de um mesmo instrumento de avaliação de desempenho de enfermeiras em três diferentes hospitais.

Outro elemento do programa de avaliaçāo a ser discutido diz respeito à freqüência com que a avaliação se realiza. A freqüência traduz o «quando» avaliar o funcionário e, embora se deva pensar na avaliação como um processo continuo, deve-se admitir, também, que há necessidade de se formalizar a avaliação periodicamente.

BERGAMINI ' estabelece três critérios que norteiam a freqüência com que as organizaçōes realizam a avaliação. O critério jurídico, que é estabelecido pela legislação trabalhista vigente e que determina a freqüência da avaliação em relação ao tempo de trabalho do indivíduo em determinada organização; o critério trabalho, que é estabelecido de acordo com a complexidade das tarefas, determinando que atividades mais simples e rotineiras devem ser avaliadas mais freqüentemente do que as mais complexas; e o critério politico, que é definido pela política de pessoal adotada na instituição e que se reflete em todo o programa de avaliação.

Para AQUINO ${ }^{1}$ e TOLEDO ${ }^{69}$, a periodicidade da avaliação comumente usada é a anual. A avaliação semestral, segundo eles, é considerada contraproducente, porque avalia apenas o potencial do indivíduo, ou seja, a capacidade de se desenvolver e não os resultados de seu trabalho. A avaliação inferior ao prazo de seis meses é aceita apenas para os recém-admitidos.

Também para CHERNUSHIN \& GALVIN ${ }^{15}$ e BERGLAS ${ }^{12}$, a freqüência mais utilizada na avaliação de enfermeiras americanas é a anual.

Um último ponto importante, e pouco discutido por administradores, diz respeito aos sentimentos que envolvem as pessoas quando participam 
do processo de julgar e ser julgado; entretanto, mesmo administradores que, na sua política de pessoal, visam a administração participativa, esquecem-se de investigar como as pessoas reagem à avaliação de desempenho.

A necessidade de se investigarem sentimentos reside no fato de a avaliação colocar, fatalmente, em jogo, necessidades humanas de apreço, auto-estima e de auto-realização.

ARGYRIS ${ }^{3}$, relatando os resultados de entrevistas feitas com funcionários imediatamente e após 12 semanas da avaliação, evidenciou a frustração destes por terem sido avaliados por seus superiores em nivel acima daquele em que eles mesmos se avaliariam. Foi evidenciada, também, a frustração dos avaliadores por não perceberem, por parte dos avaliados, gratidão pela demonstração de apreço.

Os objetivos dos programas e os sentimentos que prevalecem nas pessoas após a avaliação fornecem subsídios essenciais para a avaliação da avaliação feita; sem esta, não há informações suficientes para o aprimoramento dos programas de avaliação de desempenho e nem retroalimentação para os programas de desenvolvimento de pessoal.

$\mathrm{Na}$ área de enfermagem, JONES \& LUFKIN ${ }^{31}$ criticam o fato de não se fazer a avaliação da avaliação de desempenho das enfermeiras americanas. Segundo eles, pode-se perceber a insatisfação com o processo de avaliação, mas não se podem conhecer as causas dessa insatisfação se não se apreciar a avaliação feita.

Embora sejam encontrados, na literatura brasileira; diferentes estudos sobre a utilização da avaliação de desempenho no processo de desenvolvimento de pessoal, não encontramos, ainda, na área de enfermagem, estudos específicos sobre o assunto.

A importância do desenvolvimento dos recursos humanos em enfermagem, a influência da avaliação de desempenho nesse desenvolvimento e a escassez de literatura pertinente evidenciam a premência de tais estudos.

KURCGANT, P. Study on nurse performance evaluation: theoretical approach - Part I. Rev. Esc. Enf. USP, São Paulo, 20(1)39-54, 1986.

This first part of the study presents the literature on the evolution of personnel administration and discussess the organization/individual interaction from the mechanistic up to the systemic focusing. The systemic. approach is based on the organization sociologic concept. The performance evaluation is studied as an integral part of human resources administration which in the health area, is considered a subsystem of the health system. The objectives of evaluation area analysed as well as the methods and techniques used, the training of the individuals participating in the evaluation process, the periodicity of the evaluation process and the feelings of both the evaluator and the evaluated person. As far as nursing is concerned it is underlined what has been done on nurse performance evaluation in other countries. The lack of studies on this subject in Brasil is stressed. 


\section{REFERENCIAS BIBLIOGRĀFICAS}

1. AQUINO, C.P. Administraça de recursos humanos: uma introduç̃o. Sæa Paulo, Atlas, 1979. p.22-201.

2. Avaliação de desempenho. Rov. Paul. Hosp., São Paulo, 27(9):281-291, set. 1979.

3. ARGYRIS, C. A integraçăo individuo-organização. São Paulo, Atlas, 1975. p.1-290.

4. ARNDT, C. \& HUCKABAT, L.M.O. Avaliação e medição. In: - Administração em enfermagem. 2. ed. Rlo de Janeiro, Interamericana, 1983. p.117-130.

5. BAUMANN, A. \& BENOIT, E.H. A multidimensional toal for clinical evaluation. Nurs. Papers, Montreal, 8(2):25-30, 1976.

6. BerganinI, C.W. Avaliacão de desempenho humano na empresa. 3. ed. Såo Paulo, Atlas, 1977. $274 \mathrm{p}$.

7. Desenvolvimento de recursos humanos. Săo Paulo, Atlas, 1980. p.11-63, 126-132.

8. Bergamini, C.W. Novo exame preocupado da avaliaç̃o de desempenho. Rev. Adm., São Paulo, 18(20) :6-11, abr./jun. 1983.

9. Por que falham os sistemas de avaliacão do desempenho? São Paulo, Fundaç̃o Getúlio Vargas, 1979. p.1-27.

10. BERNARDES, C. Sociologia aplicada à administracazo: o comportamento organizacional. São Paulo, Atlas, 1982.

11. BERNHARDT, J. \& SCHUETTE, L.H.P.E.T. A method of evaluating professional nurse performance. J. Nars. Adm., Billerica, 5(8):18-21, Oct. 1975.

12. BERGLAS, C. Evaluation. Nurs. Mirror, Sussex, 142(13):64, Mar. 1976.

13. BLAU, P.M. \& SCOTT, W.R. Organizacões formais: uma abordagem comparativa. São Paulo, Atlas, 1979. D.222-223.

14. BUENo, D.J. Performance evaluation: when all is said and done more is said than done. J. Nurs. Adm.. Blllerica, 7(10):21-23, Dec. 1977.

15. CHrRnUSHIN, N. \& GALVIN, J.H. Evaluation that is frankly subjective. Amer. J. Nurs., New York, 62(2):92-93, Feb. 1962.

16. Chiaveinato, I. Administragão de recursos humanos. 2. ed. São Paulo, Atlas, 1980. v.2.

17. COELho NETO, A. Avaliação sem medo. Fortaleza, Esteves, 1980.

18. DAU, G. The appraisal process. Superv. Nurse, Chicago, 7(8):39-42, Aug. 1976.

19. DUNNETTE, M.O. Seleción y administración del personal. 2. ed. México, Continental, 1969. p.124-137.

20. etzioni, A. Organizacões modernas. 5. ed. São Paulo, Pioneira, 1976. p.9-19.

21. FLIPPo, E.B. Principios de administraç̃o de pessoal. Sz̃o Paulo, Atlas, 1976. D.287-305.

22. GAUERKE. R.D. Appraisal as a retention tool. Superv. Nurse, Chicago, 8(6) :34-37, June 1977.

23. GOLIGHTLY, C. MBO and performance appraisal. J. Nurs. Adm., Wakefield, 9(9):12-20, Sept. 1979 ,

24. GORDON, P. Evaluation - a tool in nursing service. Amer. J. Nurs., New York, 60(3): 364-66, Mar. 1960.

25. GRILLO, A.N. Avaliacão de desempenho: experiência brasileira na administração pública. Rov. Adm., São Paulo, 18(1), jan./fev. 1982.

26. GRONLUND, N. Measurement and evalution in teaching. 2. ed. New York, MacMillan, 1971. D.66-131. 
27. GROS, A. \& AUMONT, M 0 homem o empresa. Portugal, Inova Barl, 1973. p.17-21.

28. HAMRIC, A.B.; GRESHAM, L.; FCCARD, M. Staff evaluation of clinical leaders. J. Nurs. Adm.. Wakefteld, 8(1):18-26, Jan. 1978.

29. HESLIN, P. Evaluating clinical performance. Nurs. Outlook.g. New York, 11(5):344-45, May 1963.

30. JESSUP, G. \& JESSUP, H. Avaliaçăo de atıtudes. In: - Selecĭo e avaliacĩo no trabalho. Rio de Janeiro, Zahar, 1977. p.56-85.

31. JONES, M.K. \& LUFKIN, S.R. Who wants to think about an unsatisfactory evaluation? Nursinx, Horshan, 11(2) :121-126, Feb. 1981.

32. JUCIUS, M. Adminiatracão de pessoal. Săo Paulo, Saraiva, 1979. p.368-387.

33. KAST, F.E. \& ROSENZWHIG, U.E. Organisacio e adminintracĩo. Săo Paulo, Pioneira, 1976.

34. KATZ, D. \& KAfIN, R.L. Paicologia social das orcanizacóes. 2. ed. săo Paulo, Atlas, 1973. 551p.

35. KATZ, F.M. \& SNOW, R. Evaluación del rendimento do los trabajadores de Ia salud. Ginebra, Organización Mundial de la Salud, 1981. p.16-34, (Cuadernos de Salud Publica, 72).

36. KELLY, R.L. Evaluation is more than measurement. Amer. J. Nurs., New York, 73(1): 114-16, Jan. 1973.

37. KENNBDY, J.A. The meaning of evaluation. Nurs. Outlook, Now York, 9(7):438-440, July 1961.

38. KOONTZ, H. Avaliagĩo de objetivos. Rlo de Janeiro, Iivros Técnicos e Cientificos, 1974. 196 .

39. LAWLER, E. \& PORTER, L. Antecedent attitudes of efective managerial performance. Org. Behav. Hum. Pelorm., New York, 2:122-43, May 1967.

40. LTKRRT, R. A organizacão humana. Săo Paulo, Atlas, 1975. p.35.

41. LU POUR VOUS: une nouvelle méthode d'évaluation des élèves infirmières en stage. Rev. Infirm. Paris 24(5):441. Mai 1974.

42. LUCENA, M.D.S. Avaliacão de desempenho. São Paulo, McGraw Hill do Brasil, 1977. p.1-152.

43. __ Treinamento de supervisores am avaliagio do desempenho. Rio de Janeiro, CEPLAN - Assessorla, Métodos e Planejamentos, s.d. 63p.

44. MAIA, F.A. \& BUSSON, S.J. Avaliaçăo de desempenho. In: - Avaliacão do cargos e de desempenho uma nova metodologia. Rio de Janeiro, Livros Técnicos e Cientificos, 1974. p.42-54.

45. MARRINER, A. Contemporary nursing management: issues and practico. Saint Iouis, Mosby, 1982. p.22-63.

46. Evaluation of perwonnel. Superv. Nurse, Chicago, y(5):36-39, May 1976.

47. McGREgor, D. Motivacão e lideranca. Săo Paulo, Brasiliense, 1973. p.24, 159-170.

48. Um exame preocupado da avaliaço de desempenho. Frpanaxo, Săo Paulo, 2(38): 55-63, jul. 1973.

49. MEJIA, A. Processo de desarollo del personel de salud. In: HALL, T.L. \& MEJIA, A. Planificación del personel de salnd. Ginebra, OMS, 1979. p.35-63.

50. — \& FULOP, T. Planificacion del personal de salud: examen general. In: HALL, T.L. \& MEJIA, A. Planificacion del personal de Salud. Ginebra, OMS, 1979. p.9-33. 
51. MOORE, T.F. \& BIMENDINGEF, E. Evaluation as a two-way street. Superv. Nurse, Chicago, 7(6):58-9, jun. 1976.

52. NEVES, J.A.D. Proposta para um sistema de avallaçăo de desempenho para funcionários técnicos e professores. Rev. Adm., São Paulo, 15(3):74-90, Jul./set., 1980.

53. O'DONOVAN, T.R. Performance evaluation of subordinates. Superv. Nurse, Chicago, 2(11): 48-57, Nov. 1971 .

54. OLIVgIRA, M.A. Análise e solucão de problemas de desempenho na empresa. Săo Paulo, Atlas, 1977. p.11-28.

55. OUICHI, W.G. Teoria Z: como as empresas podem enfrentar o desafio japonês. Săo Paulo, Fundo Educativo Brasileiro, 1982. p.101-287.

66. PATZ, A.L. Avaliaçăo do desempenho: util mas ainda combatida. Fuxpansão, São Paulo, 4(90): :41-51, ago. 1975 .

57. REZLFR, G.G. \& STEVENS, B.J. The nurse evaluation in edncation and service. New York, McGraw Hill, 1978. D.3-249.

58. SANTOS, O.B. Orientacão e desenvolvimento do potencial humano. Săo Paulo, Pioneira, 1978. p.3-63.

59. SAYLES, L.R. Administrando as organizaç̋es: os velhos manuais devem morrer! In: HAMPTON, D.R. Conceitos de comportamento na administracăo. Săo Paulo, BPU, 1973. p.129-39.

60. SIMON, H. A capacidade de decisia - de lideranç. Săo Paulo, Fundo de Cultura, 1963.

61. —_ SMITHBURG, D.C.; THOMPSON, V. Publio adminiotration. New York, Knoph, 1950. p.5.

62. SIMS, A. The critical incident technique in evaluating student nurse performance. Int. J. Nurs. Stud, Oxford, 1s:123-130, 1976.

63. SOUTH, J.C. The performance proflle: a technique for using appraisals effectively. J. Nurs. Adm.. Wakefield, 8(1):27-31, Jan. 1978.

64. SOUZA, E.L. Clima c cultura organizacionais: como so manifeatam e como se manejam. Săo Paulo, Edgard Blücher, 1978. p.33-82.

65. STOLZ, R.K. Can appraisal interviews be made effective? Parsonnol, New York, $2(8)$ :32-41.

66. SUND, R.B. \& PICARD, A.J. Objetivos comportamentais o medidas de avallagio: cibnclas - matematica. São Paulo, EPU, 1978. p.9-127.

67. TATE, B.L. Test of a nursing performance evaluation instrument. New York, National League for Nursing, 1964. 99p. (NLN Publication, 19-1121).

68. TEJADA-DE-RIVERO, D. Introducción. In: HALL, T.I. \& MEJIA, A. Planificacion del personal de Salud. Ginebra, OMS, 1979. p.5-8.

69. TOLFDO, F. Adminietracixo de pessosl: desenvolvimento de reonrmos humanos. 5 ed. Sřo Paulo, Atlas, 1978. 208p.

70. WAHRLICH, B.M.S. Uma anślige das teorias da organisactio. Rio de Janelro, Fundacăo Getúlio Vargas, 1972.

71. WERTHER JONIOR, W.B. \& DAVIB, K. Adminimtracko do pessoal e recursos humanos. Săo Paulo, McGraw-Hill do Brasil, 1983. 4990.

72. WILFY, L. Job evaluations. Nursing, Horhham, B(11):75-80, Nov. 1975.

73. WOOLTEY, A.S. The long and tortured history of clinical evaluation. Nurs. Outlook, New York, 25(5):308-315, May 1977. 
74. WYMAN, J. \& FERNAU, K. Developing a criterion-referenced tool. Nurs. Outlook, New York, 25(9): :584-586, Sept. 1977.

75. YODER, D. Administracão de pessoal e relações industriais. São Paulo, Mestre Jou, 1969.

76. ZOFFOLI, E. Evaluación de los servicios de enfermería. Bol. Ofic. sanit. Panamer., Washington, 57(3) :250-257, sept. 1964. 